\title{
Progress towards Millennium Development Goals 4 \& 5: strengthening human resources for maternal, newborn and child health
}

Jean Christophe Fotso ${ }^{1 *}$, Linda Fogarty ${ }^{2}$

Since the 1990s, developing countries as a whole have made remarkable efforts to reduce under-five mortality rate from 90 to 48 deaths per thousand live births in 2012. As a result, the number of annual under-five deaths dropped by nearly 6 million during that period $[1,2]$. Unfortunately, the pace of reduction was slowest in sub-Saharan Africa, making it impossible that the region will reach the target for the Millennium Development Goals (MDGs) 4 [1], but a few countries, including some of the poorest such as Ethiopia, Liberia, Malawi and Niger, have already met the MDG 4 target, or are making progress that are consistent with the target [3]. At the same time, global maternal deaths have been nearly halved since the 1990 s, from 380 deaths per 100,000 live births to 210 in 2013. In sub-Saharan Africa and South Asia, the two regions where more than $85 \%$ of all maternal deaths occur, the maternal mortality ratio (MMR) dropped from 990 to 510, and from 530 to 190, respectively [2]. Skilled birth attendance (SBA), one of the proximate determinants of maternal mortality, increased only modestly during the period 1990-2012, from $40 \%$ to $53 \%$ in sub-Saharan Africa, and from 33\% to $51 \%$ in South Asia $[2,4]$. As with most health indicators, there are wide variations in the coverage of SBA from $20 \%$ or less in Ethiopia and Niger, to more than $80 \%$ in countries including Benin, Namibia and Botswana [3].

Most maternal, newborn and child deaths result from causes that can be adequately treated by a package of well-known interventions [5-7]. One of the main challenges in delivering essential and life-saving interventions to avert these deaths is the shortage of a well-trained, supervised, and motivated health workforce $[8,9]$. With the vast amount of evidence showing that increased availability of skilled health workers is directly linked to

\footnotetext{
* Correspondence: jean-christophe.fotso@concern.net

'Concern Worldwide US, New York, NY, USA

Full list of author information is available at the end of the article
}

improved maternal, newborn and child health $(\mathrm{MNCH})$ outcomes, health workforce development is increasingly seen as a critical component of MNCH care delivery [10].

\section{Human resources for $\mathrm{MNCH}$ and progress towards MDGs 4 \& 5: what have we learned?}

In the decade since the World Health Report's call to action on human resources for health (HRH) [11], tremendous global attention has been placed on strengthening human resources for $\mathrm{MNCH}$, notably by increasing the sheer number of health providers and improving the quality of $\mathrm{MNCH}$ care they provide. Though the density of skilled providers falls below the World Health Organization (WHO) threshold for obtaining adequate $\mathrm{MNCH}$ care of 23 per 10,000 people in 53 of the 68 priority countries [9] the recent attention on HRH has shed light on ways to ensure that the right health workers are in the right place providing the right care for women and children.

\section{The right health workers}

Though it is well-recognized that having a skilled birth attendant (SBA) is one of the most reliable predictors of positive maternal and neonatal health outcomes, policies supporting SBAs in the workforce are often lacking. For example, in Africa, where the global health crisis is most severe, very few national HRH policies exist to guide the training and deployment of the health workforce for maternal, newborn and child health [12]. Where policies are in place, the divide between policy and practice, including imbalances in the workforce structure and distribution, stands in the way of equitable service access, suggesting the need for a more strategic approach to health workforce management [13]. One promising tool to understand and begin to address this divide is a task analysis of the current national $\mathrm{MNCH}$ workforce, a method in use in Mozambique to streamline the workforce [14]. Such approaches are critical first steps towards 
developing the proper policies and plans required to improve the effectiveness of the public health workforce in a sustainable way $[15,16]$.

Once the right type of worker is determined for the country's needs, recruiting the right candidates and educating them in the right manner-providing up-to-date competency-based education with adequate mentored practice-is critical. With significant increases in donor funding for pre-service education (PSE), evidence in this area has grown in recent years. Johnson and colleagues developed a conceptual model of the health impacts of PSE and collected evidence of the effectiveness of common PSE input. They also highlighted the essential role of clinical preceptors, the importance of professional regulation and the effectiveness of targeted recruitment of students from rural and low-resource settings to improve health worker retention [17].

\section{...In the right place}

Even in countries where sufficient numbers of providers are available in urban centers, severe shortages exist in rural areas. In Guinea, for example, where fewer than half of nurses and a fifth of midwives needed for $\mathrm{MNCH}$ care are currently available, supply is lowest in rural areas, and demand is expected to grow by $22 \%$ in the next decade [18]. In countries where home births are still the norm, one promising method for providing women with the care they need is through community health providers. One recent analysis summarizing community-centric methods to reduce postpartum hemorrhage (PPH) reported that across 18 programs, a total of 6,732 women took misoprostol-a uterotonic that does not require refrigerationand that distribution by community health providers more than doubled coverage rates compared with health workers and ANC providers alone [19].

Another way to ensure that critical services are available where women need them is by retaining the skilled maternal health providers currently in place, by improving job satisfaction and formal supervision systems, for example [20].

\section{...Providing the right care}

Making the most of the current workforce to meet demands is essential in addressing the HRH crisis for $\mathrm{MNCH}$ care. Task-shifting has improved access and quality of care in a variety of settings [21-23]. For example, in Mali, trained matrones-or auxiliary midwiveswere as skilled at performing active management of the third stage of labor (AMTSL) as their SBA colleagues, which led to a shift in national policy [24]. Though task-shifting may not be the entire answer to the health workforce crisis, it certainly is part of the solution [25].

Quality and coverage of interventions known to improve maternal and newborn health vary widely. For example $90 \%$ of women have at least one ANC visit, but only $30 \%$ of babies receive a postnatal (PNC) visit [26]. A systematic review found that staff shortages were the most consistent barrier to quality emergency obstetric care [27]. Though increasing health worker numbers and quality-"scaling up" and "skilling up"-are both needed, Fauveau, Sherratt and de Bernis encouraged prioritizing quality over numbers, and shared a framework for addressing scaling up quality midwifery at the community level [28].

The most common "go-to" intervention to improve provider performance is in-service training. Though training is essential to develop the health workforce, Gaye and Nelson argue that training alone cannot succeed without addressing common pitfalls, including uncoordinated training, training the wrong people, taking workers from their jobs to be trained, and inattention to other factors needed to support workers' new skills, such as organizational support and supportive supervision [29]. Another recent review of in-service training approaches reports that multiple learning modalities, clinical simulations, repetition, and practice with feedback are effective techniques, while passive instruction, such as reading and lecture, have limited effect [30].

Fritzen (2007) proposed using a lens to look at what the workforce 'can do' and what it 'will do' to help improve service quality, citing clear terms of employment, supervision, employee recognition, incentives to improve motivation, and performance management techniques [12]. Quality improvement approaches have been widely used with some success, such as in Tanzania, where performance in newborn care improved, but newborn resuscitation performance remained unchanged [31].

\section{Overview of the Supplement}

Drawing largely from the evaluation of HRH projects implemented as part of Concern Worldwide US' Innovations for $M N C H$, this Supplement seeks to expand the evidence base on the critical role of human resources for MNCH in countries' efforts towards the MDGs 4 \& 5 targets. The Supplement includes four core papers. The first paper by Weiss et al. examines if supervision of Care Group (a community-based implementation strategy for the delivery of social and behavior change interventions) activities by the Burundi Ministry of Health $(\mathrm{MOH})$ personnel could achieve the same child health outcomes as supervision provided by specialized non-governmental organization (NGO) staff. Drawing on quantitative data from the evaluation which had a quasi-experimental design, the authors show that the $\mathrm{MOH}$-led Care Group model performed at least as well as the NGO-led model in achieving specific child health and nutrition outcomes. This finding suggests increased potential for sustainability. 
The second paper by Vesel at al. is based on the evaluation data of a project named Helping Health Workers Cope (HHWC), which was implemented in a rural district of Sierra Leone. The paper shows that the intervention had a positive effect on coping skills, stress levels and provider-provider and provider-client relationships, and observed associations between changes over time in coping skills and changes in relationships. The authors argue that integrating psychosocial counseling and training interventions into health worker pre-service and in-service curricula would allow the positive effects of this intervention to be expanded across other areas of Sierra Leone.

The third paper uses data from a somewhat similar project, entitled Quality Circles, which focused on interventions for both formal health workers and traditional birth attendants. Authored by Higgins-Steele et al., its results show that the intervention had positive effects on organizational skills and relationships. They also indicate that improvements over time in organizational skills variables - problem-solving, strategizing and negotiation skills - were strongly associated with a change in some of the relationship variables. The authors conclude that this approach of bringing together peers in a structured process of group work and individual skill development is critical in low-resources contexts, where active participation and resourcefulness of health workers can contribute to better health service delivery.

The fourth paper by Fotso et al. shifts the geographic focus from Africa to rural India, specifically in the context of community-based $\mathrm{MNCH}$ service delivery by female Community Health Workers (CHWs), known as Accredited Social Health Activists (ASHAs). Examining the influence of a male engagement project on the utilization and community-based delivery of $\mathrm{MNCH}$ care in a rural district of India, the authors found gender-based divisions of work and space in core areas of delivery and use of $\mathrm{MNCH}$ services. The study ultimately unveils the complementarity of male and female CHWs in the community-based delivery of, and increased demand for, $\mathrm{MNCH}$ services.

Finally, the concluding commentary by Lehmann casts the four papers in the broader context of human resources strengthening for health systems resilience. The author suggests that the interventions reviewed by this set of papers be viewed along a continuum of program strengthening and systems resilience: repairing damage caused in the past, strengthening systems going forward, and introducing new actors by extending traditionally female-dominated community-level care to include men. The commentary ends with critical questions related to scale up and sustainability.

\section{About the Innovations for $\mathrm{MNCH}$ initiative}

The Innovations for Maternal, Newborn and Child Health is an Initiative of Concern Worldwide US. It seeks to develop and test innovative interventions and strategies to address common barriers that prevent essential health services from reaching women and children. It is supported by a multi-year grant from the Bill \& Melinda Gates Foundation. The initiative started in 2010 with comprehensive research on the most pervasive barriers to the delivery of $\mathrm{MNCH}$ services, and then generated intervention ideas to address those barriers. The process engaged communities in low-resource settings, tapped unheard or unconventional voices at both global and country levels, and honed the ideas through cross-disciplinary inputs from experts from many different fields. A first set of projects (referred to as Phase I) were designed, implemented and evaluated between 2009 and 2013 (See Additional file 1). From the initial basket of ideas, the learnings from Phase I, and additional formative research in selected countries, five additional projects were designed and launched in 2013 and 2014 (see Additional file 2).

The Innovations for MNCH's research, monitoring and evaluation (RME) plan aims to determine the effectiveness of the interventions in overcoming the identified barriers to $\mathrm{MNCH}$ services, and to explore how and why the interventions achieved their results. Data sources include routine monitoring, baseline and endline assessments and process documentation. Also important to the initiative's overall strategy is the experimentation and learning related to the application of human-centered design in $\mathrm{MNCH}$ in developing country settings [32]. Another novelty associated with Innovations for $\mathrm{MNCH}$ is the incorporation of human rights principles into project and research designs. Drawing from major UN frameworks and with inputs from UNICEF and external experts, Innovations developed its human rights framework around four principles: right to health, non-discrimination, participation, and accountability [33,34]. These research components are being used to inform new approaches to program design, generate evidence about the effectiveness of the interventions, and shed light on the potential of human-centered design and the application of human rights principles in $\mathrm{MNCH}$.

\section{Additional material}

\section{Additional file 1: Annex 1}

Additional file 2: Annex 2

Competing interests

The authors declare no competing interests.

Authors' contributions

JCF and LF conceptualized the study, wrote the manuscript, and approved the final version. 


\section{Acknowledgements}

Innovations for Maternal, Newborn \& Child Health (Innovations) is an initiative of Concern Worldwide U.S. funded through a multi-year grant from the Bill \& Melinda Gates Foundation. UNICEF is Innovations' global partner. The scope of relationship between Innovations and UNICEF is captured in a Memorandum of Understanding under which a staff member of Concern Worldwide US serves as the focal point within UNICEF to promote joint work and facilitate knowledge-sharing between the two organizations. Options UK was the global research partner for Phase I, and John Snow, Inc. (JSI) is the global research partner for Phase II. Ms. Allison Smith-Estelle copy edited all papers of this Supplement. We would like to thank the reviewers for their comments.

\section{Declarations}

The publication costs for this article were funded by the Innovations for Maternal, Newborn \& Child Health, an initiative funded by Bill \& Melinda Gates Foundation.

This article has been published as part of BMC Health Services Research Volume 15 Supplement 1, 2015: Improved access to maternal, newborn and child health services: strengthening human resources for health. The full contents of the supplement are available online at http://www. biomedcentral.com/bmchealthservres/supplements/15/S1.

\section{Authors' details}

'Concern Worldwide US, New York, NY, USA. ${ }^{2}$ Jhpiego, Baltimore, MD, USA.

Published: 8 June 2015

\section{References}

1. UNICEF: Committing to Child Survival: A Promise Renewed Progress Report 2013. UNICEF, New York, 2013; 2013.

2. UN (United Nations): "The Millennium Development Goals Report 2013.". United Nations, New York, 2014; 2014.

3. United Nations Economic Commission for Africa (UNECA), African Union (AU), African Development Bank (AfDB), United Nations Development Programme (UNDP): Assessing Progress in Africa toward the Millennium Development Goals: Analysis of the Common African Position on the Post-2015 Development Agenda. Addis Ababa, Ethiopia, 2014; 2014.

4. WHO: Fulfilling the Health Agenda for Women and Children: the 2014 Report. World Health Organization, Geneva, 2014; 2014.

5. UN (United Nations): Global Strategy for Women's and Children's Health. United Nations, New York, 2010; 2010.

6. Black RE, Cousen $\mathrm{S}$, Johnson $\mathrm{HL}$, et al: Global, regional, and national causes of child mortality in 2008: a systematic analysis. Lancet 2010, 375(9730):1969-1987.

7. de Sousa A, Tiedje KE, Recht J, Bjelic I, Hamer DH: "Community case management of childhood illnesses: policy and implementation in Countdown to 2015 countries.". Bulletin of the World Health Organization 2012, 90:183-190.

8. Chen L, Evans T, Anand S, Boufford Jl, Brown H, Chowdhury M, et al: Human resources for health: overcoming the crisis. Lancet 2004, 364(9449):1984-1990.

9. Buchan J, Couper ID, Tangcharoensathien V, Thepannya K, et al: Early implementation of WHO recommendation for retention of health workers in remote and rural areas. Bulletin of the World Health Organization 2013, 91(110):834-840.

10. Gupta N, Maliqi B, França A, Nyonator F, Pate MA, Sanders D, et al: Human resources for maternal, newborn and child health: from measurement and planning to performance for improved health outcomes. Human Resources for Health 2011, 9:16.

11. WHO: The world health report 2006: working together for health. Geneva, World Health Organization, 2006; 2006.

12. Murphy GT, Goma F, Mackenzie A, Bradish S, Price S, Nzala S, Rose AE, Rigby J, Muzongwe C, Chizuni N, Carey A, Hamavhwa D: A scoping review of training and deployment policies for human resources for health for maternal, newborn, and child health in rural Africa. Human Resources for Health 2014, 12:72.

13. Fritzen SA: Strategic management of the health workforce in developing countries: what have we learned? Human Resources for Health 2007, 5:4.

14. Dgedge M, Mendoza A, Necochea E, Bossemeyer D, Rajabo M, Fullerton J: Assessment of the nursing skill mix in Mozambique using a task analysis methodology. Human Resources for Health 2014, 12(1):5.
15. Dussault G, Dubois CA: Human resources for health policies: a critical component in health policies. Human Resources for Health 2003, 1(1):1.

16. Beaglehole R, Dal Poz MR: Public health workforce: challenges and policy issues. Human Resources for Health 2003, 1:4.

17. Johnson P, Fogarty L, Fullerton J, Bluestone J, Drake M: An integrative review and evidence-based conceptual model of the essential components of pre-service education. Human Resources for Health 2013, 11:42.

18. Jansen C, Codjia L, Cometto G, Yansané ML, Dieleman M: Realizing universal health coverage for maternal health services in the Republic of Guinea: the use of workforce projections to design health labor market interventions. Risk Management and Healthcare Policy 2014, 7:219-232.

19. Smith JM, Gubin R, Holston M, Fullerton J, Prata N: Misoprostol for postpartum hemorrhage prevention at home birth: an integrative review of global implementation experience to date. 2013, 13:44.

20. McAuliffe E, Daly M, Kamwendo F, Masanja H, Sidat M, de Pinho H: The critical role of supervision in retaining staff in obstetric services: a three country study. PLoS One 2013, 8(3):e58415.

21. Huicho L, Scherpbier RW, Nkowane AM, Victora CG, Multi-Country Evaluation of IMCI Study Group: How much does quality of child care vary between health workers with differing durations of training? An observational multicountry study. Lancet 2008, 372(9642):910-916.

22. Chilopora G, Pereira C, Kamwendo F, Chimbiri A, Malunga E, Bergstrom S: Postoperative outcome of caesarean sections and other major emergency obstetric surgery by clinical officers and medical officers in Malawi. Human Resources for Health 2007, 5:17.

23. Morris MB, Chapula BT, Chi BH, Mwango A, Chi HF, Mwanza J, et al: Use of task-shifting to rapidly scale-up HIV treatment services: experiences from Lusaka, Zambia. BMC Health Services Research 2009, 9:5.

24. Stilwell B, Nelson D: Linking Challenges, Sharing Solutions: The Global Crisis in Human Resources for Health. N C Med J 2010, 71(5):464-466.

25. Lehmann U, Damme W, Barten F, Sanders D: Task shifting: the answer to the human resources crisis in Africa? Human Resources for Health 2009, 7:49.

26. WHO: Fulfilling the Health agenda for Women and Children. Geneva: World Health Organization. 2014; 2014.

27. Dogba M, Fournier P: Human resources and the quality of emergency obstetric care in developing countries: a systematic review of the literature. Human Resources for Health 2009, 7:7.

28. Fauveau V, Sherratt DR, de Bernis L: Human resources for maternal health: multi-purpose or specialists? Human Resources for Health 2008, 6:21.

29. Gaye PA, Nelson D: Effective scale-up: avoiding the same old traps. Human Resources for Health 2009, 7:2.

30. Bluestone J, Johnson P, Fullerton J, Carr C, Alderman J, BonTempo J: Effective in-service training design and delivery: evidence from an integrative literature review. Human Resources for Health 2013, 11:51.

31. Makene C, Plotkin M, Currie S, Bishanga D, Ugwi $P$, Louis $H$, et al: Improvements in newborn care and newborn resuscitation following a quality improvement program at scale: results from a before and after study in Tanzania. FY15 BMC Pregnancy Childbirth 2014, 14:381.

32. Brown T, Wyatt J: Design Thinking for Social Innovation. Stanford Social Innovation Review 2010, 31-35, Winter.

33. Gruskin S, Bogecho D, Ferguson L: Rights-based approaches to health policies and program: Articulations, ambiguities, and assessment. Journal of Public Health Policy 2010, 31(2):129-145.

34. UNICEF: Global Evaluation of the Application of a Human Rights Based Approach to UNICEF Programming. UNICEF, New York, 2012; 2012.

doi:10.1186/1472-6963-15-S1-S1

Cite this article as: Fotso and Fogarty: Progress towards Millennium Development Goals 4 \& 5: strengthening human resources for maternal, newborn and child health. BMC Health Services Research 2015 15(Suppl 1):S1. 